BMJ Paediatrics Open

\title{
Spirometry monitoring in asthmatic children in Lombardy Region, Italy
}

\author{
Pietro Casartelli, ${ }^{1,2}$ Antonio Clavenna, ${ }^{1}$ Massimo Cartabia, ${ }^{1}$ Angela Bortolotti, ${ }^{3}$ \\ Ida Fortino, ${ }^{3}$ Luca Merlino, ${ }^{3}$ Andrea Biondi, ${ }^{2}$ Maurizio Bonati ${ }^{1}$
}

To cite: Casartelli $P$, Clavenna A, Cartabia M, et al. Spirometry monitoring in asthmatic children in Lombardy Region, Italy. BMJ Paediatrics Open 2018;2:e000334. doi:10.1136/ bmjpo-2018-000334

Received 14 June 2018 Revised 7 September 2018 Accepted 11 September 2018

\section{Check for updates}

(c) Author(s) (or their employer(s)) 2018. Re-use permitted under CC BY-NC. No commercial re-use. See rights and permissions. Published by BMJ.

${ }^{1}$ Laboratory for Mother and Child Health, Department of Public Health, Istituto di Ricerche Farmacologiche Mario Negri IRCCS, Milan, Italy ${ }^{2}$ Department of Pediatrics, Hospital S Gerardo/Fondazione MBBM, University of MilanoBicocca, Monza, Italy ${ }^{3}$ Regional Health Ministry, Lombardy Region, Milan, Italy

Correspondence to Dr Antonio Clavenna; antonio. clavenna@marionegri.it

\section{ABSTRACT}

Objectives To evaluate the diagnostic and therapeutic approaches in a cohort of asthmatic children before and after starting drug therapy.

Methods Data were retrieved from administrative databases of the Lombardy Region. The study population was composed of 78184 children born in the Lombardy Region in 2002 and followed until their 10th birthday. Children with at least one antiasthmatic drug prescription per year (with the exclusion of nebulised suspension/solution formulations) in 2 consecutive years and at least one antiasthmatic drug prescription after the fifth birthday were identified as potential asthmatics $(\mathrm{PA})$. Each PA was monitored for a period starting from 12 months before and ending 24 months after the first prescription (index prescription, IP). During the monitoring period antiasthmatic drug prescriptions were analysed, as well as spirometry and/or specialist visits.

Results A total of 59975 children (76.7\%) received $\geq 1$ prescription of antiasthmatic drugs in their first 10 years of life, and $4475(5.7 \%)$ were identified as PAs. In all, $24 \%$ of PAs started with short-acting $\beta 2$-agonists (SABA), 23\% with inhaled corticosteroids (ICS) and 20\% with SABA+ICS. A total of $33 \%$ of PAs had at least one prescription for specialist visit/spirometry: $11 \%$ before and $28 \%$ after the IP. The factors associated with a greater likelihood of receiving visit/spirometry prescriptions were local health unit of residence, age and high use of asthma drugs.

Conclusions Despite international guideline recommendations, spirometry monitoring is still underused in asthmatic children, even in subjects who initiated pharmacological treatment and therefore need an airway function evaluation. Moreover, the choice of drug therapy appears not always rational, since one out of four children were commenced on ICS as monotherapy.

\section{INTRODUCTION}

Asthma is one of the most common chronic diseases in childhood, and it represents a huge burden for patients and their families. ${ }^{12}$

An appropriate drug therapy is one of the mainstays of asthma management, with the aim to achieve good control of symptoms, maintain normal activity levels and minimise future risk of exacerbations. ${ }^{34}$

A stepwise approach is recommended in introducing and adjusting controller anti-inflammatory medications, starting with inhaled

\section{What is already known on this topic?}

- Asthma is one of the most common chronic diseases in childhood, and it requires appropriate drug therapy and a periodic monitoring of airway function.

- Studies evaluating asthma management documented an underuse of spirometry and under/overuse of drug therapy.

\section{What this study hopes to add?}

Almost one in four children with potential asthma were commenced on inhaled corticosteroids as monotherapy.

- In the first 24 months of treatment, only $22 \%$ of children continued the initial drug therapy without changes.

- Underutilisation of spirometry monitoring was observed, suggesting that a gap exists between clinica practice and guideline recommendations.

corticosteroids (ICS) at a dose appropriate to asthma severity.

Periodic monitoring of airway function is also needed in order to obtain objective measures of lung function and optimise asthma control. Guidelines for the diagnosis and treatment of asthma in childhood recommend the use of spirometry every $1-2$ years or more frequently, and always at the following times: at the initial assessment; after treatment is initiated and symptoms have stabilised; and during periods of progressive or prolonged loss of asthma control. ${ }^{34}$

Despite guideline recommendations, we previously reported that only $30 \%$ of the total of potential asthmatic (PA) children and adolescents underwent spirometry testing during a 1 year observation period, with a greater prevalence in boys than in girls. ${ }^{5}$

No data are available concerning the monitoring of airway function in Italian children who initiated an asthma treatment.

The aim of the study was, therefore, to evaluate the diagnostic and therapeutic approaches, and in particular the frequency 
of spirometry testing, in a cohort of asthmatic children before and after starting drug therapy by using the administrative healthcare databases.

\section{PATIENTS AND METHODS}

\section{Data sources}

Data were retrieved from administrative databases of the Lombardy Region, one of the largest Italian regions, and the most prominent from the demographic $(16 \%$ of the Italian population) and socioeconomic points of view. In particular, three databases were analysed: a database collecting prescriptions dispensed by pharmacies in the Lombardy Region and reimbursed by the Italian National Health Service; a hospital discharge form database; and a database collecting prescriptions for diagnostic tests and specialist visits performed in hospital outpatient ambulatories. ${ }^{5}$ Data were collected and analysed using an anonymous patient code.

The study population was composed of 78184 children (male/female ratio: 1.06) born in the Lombardy Region in 2002 and followed up until their 10th birthday. Only children resident in the region for all their first 10 years of life were included.

The local health unit (LHU) of residence at birth was considered as the LHU of residence over the whole study period, using the LHU classification whose last updated date was 31 December 2012. Antiasthmatics were classified as drugs belonging to the R03 main therapeutic group of the Anatomical Therapeutic Chemical classification system.

\section{Definition of PA}

Antiasthmatic drug prescriptions dispensed to the cohort of children during their first 10 years of life were recorded and children were identified as PAs if they received one or more antiasthmatic prescriptions per year in 2 consecutive years, with at least one prescription occurring after the fifth birthday.

The latter criteria were used to exclude subjects with preschool wheezing that disappeared by school age.

Children receiving exclusively antiasthmatic drugs in nebulised suspension/solution were excluded, due to the inappropriate use of this formulation in Italy. ${ }^{6}$

This strategy for the identification of the cases has been validated in a previous study, showing high sensitivity $(90 \%)$ and specificity (98\%) in identifying asthmatic children. ${ }^{7}$

The first antiasthmatic drug prescription followed by 2 consecutive years of therapy was defined the 'index prescription' (IP).

Each subject was monitored for a period starting from 12 months before and ending 24 months after the IP. During the monitoring period the following measures were analysed:

- Per cent of subjects receiving $\geq 1$ spirometry prescription (performed in a hospital outpatient service).
- Per cent of subjects with $\geq 1$ specialist visit prescription (in an allergology or pneumology outpatient department).

- Per cent of subjects with clinical/spirometric monitoring ( $\geq 1$ prescription for spirometry or specialist visit).

This latter was considered the main endpoint, taking into account the possibility that spirometry was performed during the visit without the claim having been inserted in the database.

With the aim to monitor the intensity of drug therapy (potential proxy of the severity of the symptoms), antiasthmatic prescriptions (with the exclusion of the nebulised formulation) dispensed during the 24 months after the IP were collected, and PAs who received more than eight prescriptions (representing the 75th percentile of the distribution of antiasthmatic prescriptions by PA) were defined as 'high users'.

Moreover, the number of PAs with oral steroid prescriptions was analysed as a proxy of severe exacerbations.

Changes in asthma therapy during the 2 years after the IP were also monitored, and four profiles were identified:

- Continuers: subjects who continued with the initial therapy.

- Switchers: subjects receiving a different antiasthmatic therapy than the one prescribed at the IP, but with the same number of active substances.

- Add-ons: subjects receiving at the end of the 24 months' observation period one or more new antiasthmatic drugs in addition to the initial therapy.

- Step-downs: subjects receiving less antiasthmatic drugs, at the end of the 2 years, than the ones prescribed at the IP.

For the above analyses only children with a 24-month follow-up period after their first antiasthmatic prescription were included (ie, children who received the IP after their eighth birthday were excluded).

In the case of switchers and children with step-down, we considered an antiasthma drug stopped if there were no prescriptions for 6 or more months.

\section{Statistical analysis}

The $\mathrm{X}^{2}$ test was used to compare the incidence of PAs by gender, to compare the proportion of children with changes in therapy after the IP, and to compare the proportion of PAs with clinical and/or spirometric monitoring before and after the IP by gender, age $(<5$ vs $\geq 5$ years) and in high versus non-high users.

The relationship between the incidence of PAs and the proportion of subjects being monitored by LHU was investigated using the non-parametric Spearman rank correlation test.

A stepwise logistic regression analysis was performed with the aim to evaluate the determinants associated with a greater likelihood of monitoring. The dependent variable was the combined index of specialistic/spirometric monitoring (yes/no), while the independent variables were: age ( $<5 \mathrm{vs} \geq 5$ years), gender, LHU of residence, the 


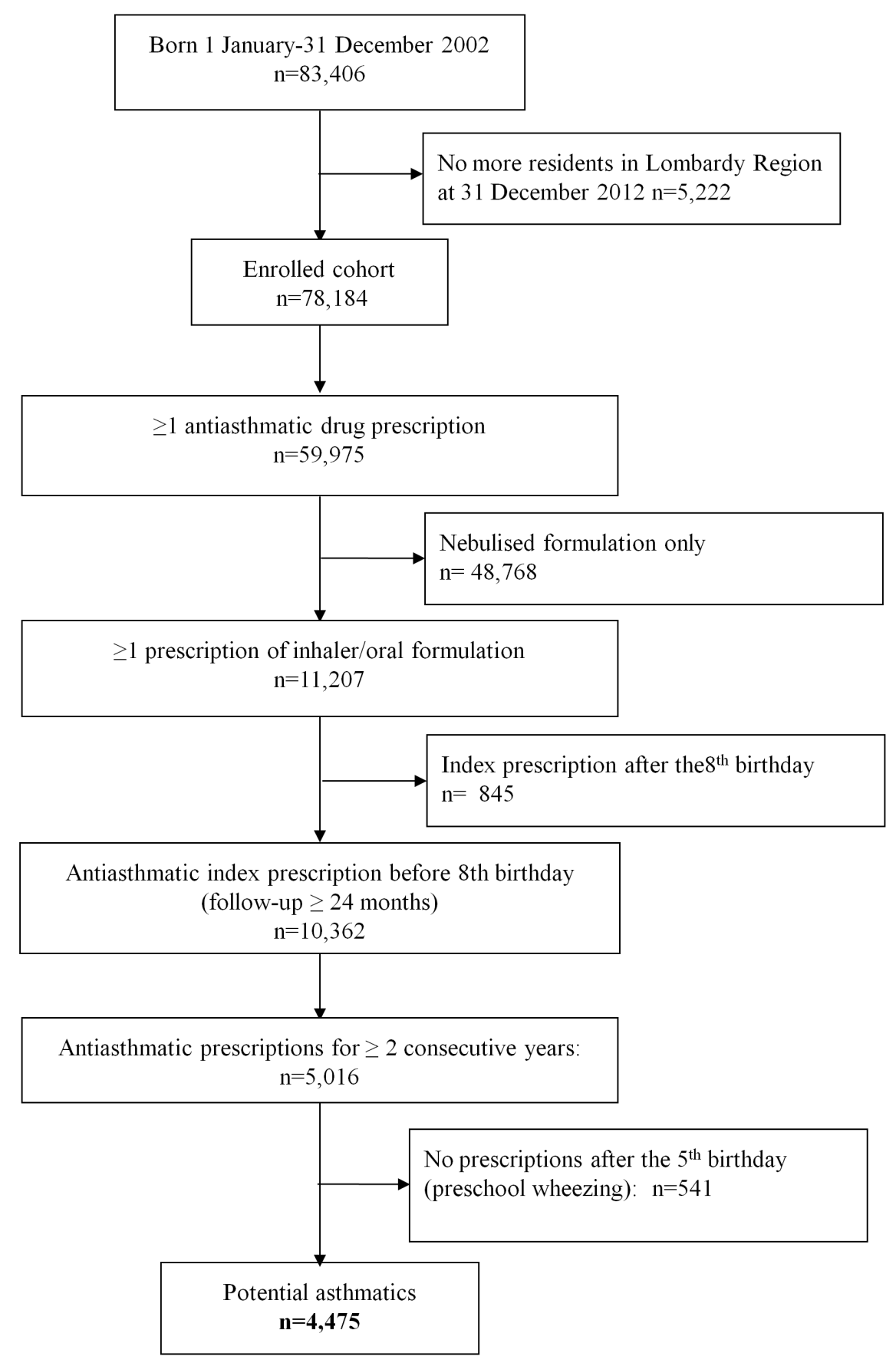

Figure 1 Cohort flow diagram.

number of antiasthmatic prescriptions $(<4,4-8,>8)$ and oral steroid prescription (yes/no) during the 24 months after IP. A significance level of 0.1 was required to allow a variable into the model. The model fit was assessed by computing the Hosmer-Lemeshow goodness-of-fit test.

\section{RESULTS}

During the study period, 59975 children $(76.7 \%$ of the study population) received $\geq 1$ prescription for antiasthmatic drugs (figure 1).

The PAs were 4475 (5.7\%) with a male/female prevalence ratio of 1.71. In all, 2553 children (57\% of the PAs) had their IP when they were under 5 years old and continued their asthma therapy after their fifth birthday. Incidence of PAs was minimal in the first 3 years of life $(0.2 \%-0.4 \%)$, had a peak at 4 years of age $(1 \%)$ 


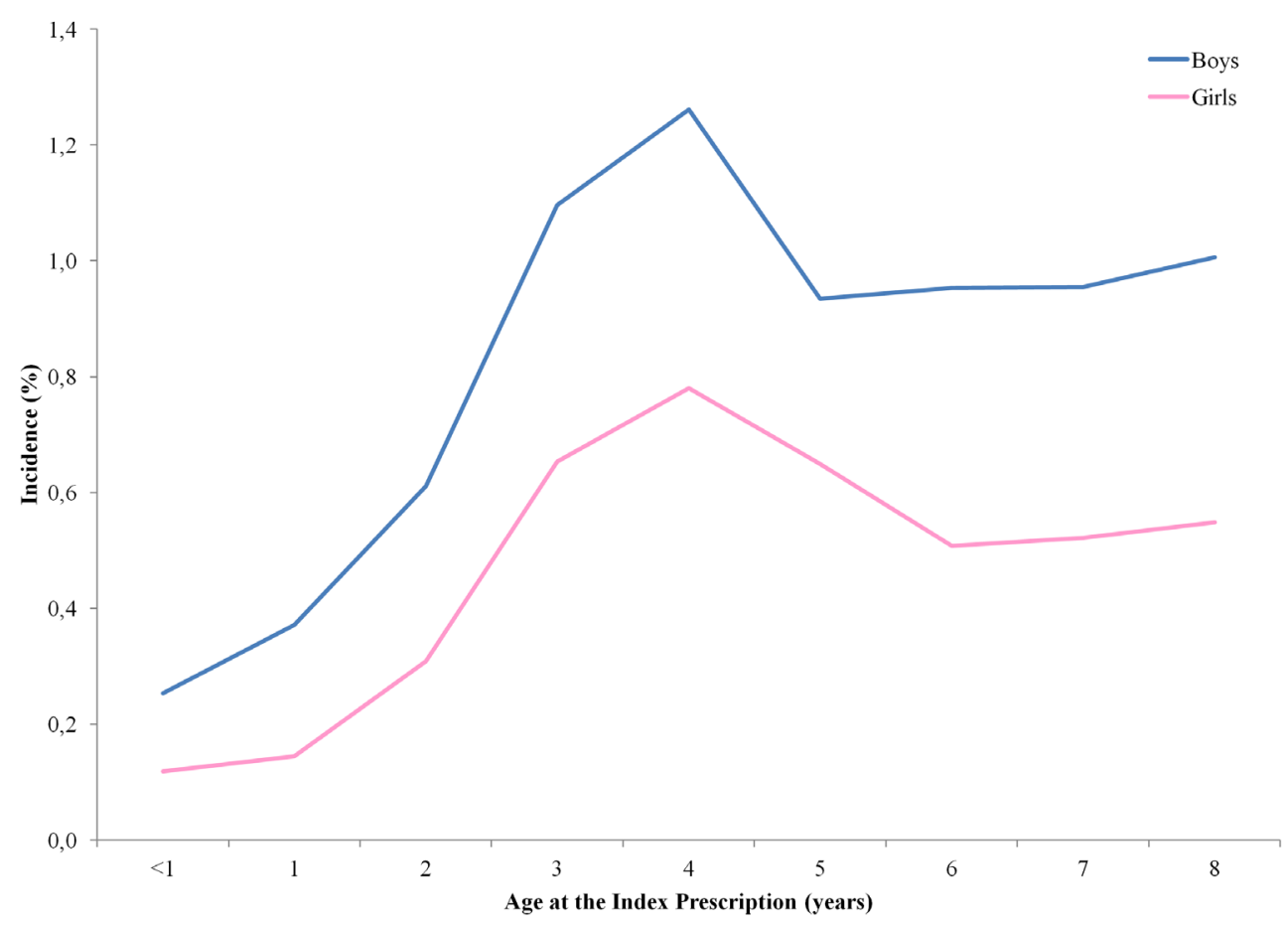

Figure 2 Incidence (\%) of (potential) asthma by gender and age.

and subsequently settled around $0.8 \%$ (figure 2). Incidence was higher in males than females $\left(\chi^{2} \mathrm{M}\right.$ vs $\mathrm{F}=337$, $\mathrm{p}<0.001)$ and ranged from $3.9 \%$ to $8.9 \%$ between LHUs.

\section{Prescription profile}

During the observation period $84.2 \%$ of the PA children received inhaled short-acting $\beta 2$-agonists (SABA), 78.9\% received ICS, $48.3 \%$ received a leukotriene receptor antagonist (LTRA) and $41.0 \%$ an association of steroids with other antiasthmatic drugs. The most commonly prescribed drugs were salbutamol $(75.5 \%$ of the subjects), fluticasone $(64.9 \%)$, montelukast (39.9\%) and a fixed combination of salmeterol and fluticasone (25.2\%) (table 1).

In the 2 years following the IP, each child received a mean of $7.2(\mathrm{SD}=5.1)$ and a median of 5 antiasthmatic prescriptions (IQR: 3-8).

\begin{tabular}{|c|c|c|c|c|}
\hline \multirow[b]{2}{*}{ Drug } & \multicolumn{2}{|c|}{ Treated children } & \multicolumn{2}{|c|}{ Prescriptions } \\
\hline & $\mathbf{n}$ & $\%$ & $\mathbf{n}$ & $\%$ \\
\hline Salbutamol & 3379 & 75.5 & 7801 & 24.6 \\
\hline Fluticasone & 2903 & 64.9 & 9414 & 29.7 \\
\hline Montelukast & 1785 & 39.9 & 8434 & 26.6 \\
\hline Salmeterol+fluticasone & 1128 & 25.2 & 3439 & 10.9 \\
\hline Budesonide & 401 & 9.0 & 973 & 3.1 \\
\hline Salbutamol+sodium cromoglicate & 347 & 7.8 & 889 & 2.8 \\
\hline Beclometasone & 108 & 2.4 & 215 & 0.7 \\
\hline Salmeterol & 75 & 1.7 & 137 & 0.4 \\
\hline Nedocromil & 62 & 1.4 & 169 & 0.5 \\
\hline Formoterol+budesonide & 42 & 0.9 & 83 & 0.3 \\
\hline Others $(n=14)$ & NA & NA & 108 & 0.3 \\
\hline Overall & 4475 & 100 & 31662 & 100 \\
\hline
\end{tabular}

NA, not applicable. 
Table 2 Distribution of antiasthmatic drugs at the index prescription by number of treated children

\begin{tabular}{lrr}
\hline & $\mathbf{n}$ & $\%$ \\
\hline Monotherapy & & \\
\hline Salbutamol & 1044 & 23.3 \\
\hline Fluticasone & 893 & 20.0 \\
\hline Montelukast & 595 & 13.3 \\
\hline Budesonide & 103 & 2.3 \\
\hline Nedocromil & 17 & 0.4 \\
\hline Beclometasone & 16 & 0.4 \\
\hline Others & 19 & 0.4 \\
\hline Overall & 2687 & 60.0 \\
\hline Polytherapy & & \\
\hline Salbutamol, fluticasone & 761 & 17.0 \\
\hline Salmeterol+fluticasone & 316 & 7.1 \\
\hline Salbutamol+sodium cromoglicate & 185 & 4.1 \\
\hline Fluticasone, montelukast & 85 & 1.9 \\
\hline Salbutamol, budesonide & 82 & 1.8 \\
\hline Salbutamol, salmeterol+fluticasone & 72 & 1.6 \\
\hline Salbutamol, fluticasone, montelukast & 46 & 1.0 \\
\hline Salbutamol, montelukast & 37 & 0.8 \\
\hline Montelukast, salmeterol+fluticasone & 34 & 0.8 \\
\hline Salbutamol, beclometasone & 30 & 0.7 \\
\hline Others & 140 & 3.1 \\
\hline Overall & 1788 & 40.0 \\
\hline
\end{tabular}

The analysis of the IPs showed that $60 \%$ of the PAs started with a single drug: $38 \%$ had a prescription of SABA, $37 \%$ received an ICS and 22\% an LTRA (table 2).

Half of the subjects starting with a polytherapy received a SABA and an ICS (separately or in fixed combination) as the IP.

The most prescribed active substances at the IP were salbutamol alone $(23.3 \%)$, fluticasone alone $(20.0 \%)$ and salbutamol and fluticasone in fixed combination $(17.0 \%)$. Comparing the therapy prescribed at the IP with the steps described in the guidelines, ${ }^{34}$ we observed that $24 \%$ of the patients started with a first-step therapy, while $15 \%$ started with a third-step therapy, mainly ICS, and long-acting $\beta 2$-agonists (LABA) ( $11 \%$ in children $<5$ years and $21 \%$ in those $\geq 5$ years old).
In the 2 years following the IP, only $22 \%$ of the PAs continued with the initial antiasthmatic therapy (table 3 ).

People starting with more than one asthma medication were more likely to have a change in their therapy $(85 \%$ vs $74 \% ; \chi^{2}=87, \mathrm{p}<0.001$ )

A total of 1295 PA children $(28.9 \%)$ were identified as high users. The prevalence of high users in the population was $1.6 \%$, and it was greater in boys than in girls $\left(2.1 \%\right.$ vs $1.2 \%$, respectively; $\left.\chi^{2}=103, p<0001\right)$.

In all, 34\% of PAs received at least one prescription of oral steroids in the 24 months after the IP.

\section{Monitoring}

Table 4 reports the proportion of PAs with prescriptions for specialist visits and spirometric testing in the 12 months before and 24 months after the IP, stratified by age at the IP. During the 3 years' follow-up, $17.8 \%$ of the PAs were prescribed a specialist visit, $20.8 \%$ at least one spirometry and $32.6 \%$ a visit and/or a spirometry.

For all the above indicators no significant differences were found between boys and girls, while a higher rate was observed in children $\geq 5$ compared with those $<5$ years old; the greatest difference was observed for spirometry $\left(32.4 \%\right.$ vs $\left.8.7 \% ; \chi^{2}=81 ; p<0.001\right)$ while the proportion of PAs with specialist visit prescriptions was similar in the two age groups ( 19.0 vs $\left.16.5 \% ; \chi^{2}=4.7 ; p=0.016\right)$.

The proportion of children with specialist visit/spirometry in the 24 months after the IP was greater in PAs whose pharmacotherapy was modified compared with continuers ( $30 \%$ vs $20 \%$, respectively; $\left.\chi^{2}=39 ; \mathrm{p}<0.001\right)$.

A slightly higher rate of spirometry testing was found in high users compared with non-high users: $26.9 \%$ vs $18.3 \%\left(\chi_{\mathrm{M}-\mathrm{H}}^{2}=46 ; \mathrm{p}<0.001\right)$, and similar findings were observed when comparing the monitoring combined index $\left(37.6 \%\right.$ vs $\left.30.6 \% ; \chi_{\mathrm{M}-\mathrm{H}}^{2}=46 ; \mathrm{p}<0.001\right)$.

A wide geographical variability was observed in the proportion of PAs with monitoring, which ranged from $22 \%$ to $56 \%$ at LHU level. An inverse rank correlation was observed at LHU level between asthma incidence and the percentage of PAs with a specialist visit or spirometry $\left(r_{s}=-0.6464 ; p=0.0092\right)$.

According to the results of the stepwise logistic regression, the LHU of residence, the number of antiasthmatic prescriptions in the 2years after the IP (as a proxy of disease severity) and the age at the IP were the variables that mainly influenced the likelihood to receive a visit

Table 3 Distribution of potential asthmatic (PA) children by pattern of therapy at the index prescription (IP) and in the 24 months after the IP. Number of PAs and (\%) are reported

\begin{tabular}{llllll}
\hline \multirow{2}{*}{ Type of IP } & \multicolumn{2}{l}{ Pattern in the 24 months after the IP } & & \multirow{2}{*}{ Total } \\
\cline { 2 - 5 } & Continuers & Switch & Add-on & Step-down & NA \\
\hline Monotherapy & $708(26.3)$ & $1483(55.2)$ & $496(18.5)$ & 2687 \\
Polytherapy & $261(14.5)$ & $534(29.8)$ & $124(6.9)$ & $869(48.6)$ & 1788 \\
All & $969(21.6)$ & $2017(45.0)$ & $620(13.2)$ & $869(19.4)$ & 4475 \\
\hline
\end{tabular}

NA, not applicable. 
Table 4 Number and \% of PAs receiving spirometry testing and/or specialist visit prescriptions in the 12 months before (IP-12) and 24 months after (IP+24) the index prescription

\begin{tabular}{|c|c|c|c|c|c|c|c|}
\hline \multicolumn{4}{|c|}{ Age at the index prescription $\mathrm{IP}-12$ months } & \multicolumn{2}{|c|}{ IP+24 months } & \multicolumn{2}{|c|}{ Overall } \\
\hline (years) & & $n$ & $\%$ & $n$ & $\%$ & $\mathrm{n}$ & $\%$ \\
\hline \multirow[t]{3}{*}{ (A) Spirometry } & $\leq 4$ & 15 & 0.7 & 184 & 8.4 & 189 & 8.7 \\
\hline & $5-8$ & 146 & 6.4 & 682 & 29.7 & 742 & 32.4 \\
\hline & All & 161 & 3.6 & 866 & 19.4 & 931 & 20.8 \\
\hline \multirow{3}{*}{$\begin{array}{l}\text { (B) Specialist } \\
\text { visit }\end{array}$} & $\leq 4$ & 182 & 8.3 & 264 & 12.1 & 361 & 16.5 \\
\hline & $5-8$ & 203 & 8.9 & 346 & 15.1 & 436 & 19.0 \\
\hline & All & 385 & 8.6 & 610 & 13.6 & 797 & 17.8 \\
\hline \multirow{3}{*}{$\begin{array}{l}\text { Monitoring (A } \\
\text { or } \mathrm{B} \text { ) }\end{array}$} & $\leq 4$ & 191 & 8.8 & 396 & 18.2 & 485 & 22.2 \\
\hline & $5-8$ & 307 & 13.4 & 859 & 37.5 & 975 & 42.5 \\
\hline & All & 498 & 11.1 & 1.255 & 28.0 & 1.460 & 32.6 \\
\hline
\end{tabular}

IP, index prescription; PA, potential asthmatic.

or a spirometry prescription (table 5). On the contrary, gender was not associated with spirometry monitoring. The model was well calibrated (Hosmer-Lemeshow goodness-of-fit test, $\mathrm{p}=0.486$ ).

\section{DISCUSSION}

To the best of our knowledge, this study was the first that monitored a cohort of asthmatic children before and after the start of the pharmacological therapy in Italy by using administrative databases.

In our study we estimated a prevalence of asthma in the first 10 years of life of $5.7 \%$. This estimate is quite consistent with other findings from studies based on administrative databases (eg, 2.6\% in Denmark, $5.4 \%$ in Norway), but lower than previous Italian estimates derived from questionnaires $(9 \%) \cdot{ }^{8-10}$

Table 5 Factors associated with a greater likelihood of specialistic/spirometric monitoring (logistic regression analysis)

\begin{tabular}{|c|c|}
\hline Variable & Adjusted OR (95\% Cl) \\
\hline \multicolumn{2}{|l|}{ LHU } \\
\hline Maxim & $4.52(2.60$ to 7.86$)$ \\
\hline \multicolumn{2}{|c|}{ Age at the index prescription (years) } \\
\hline $5-8$ & 2.91 (2.51 to 3.39$)$ \\
\hline$\leq 4$ & 1 \\
\hline \multicolumn{2}{|c|}{ Number of drug prescriptions in the 24 months after the IP } \\
\hline$>8$ & $2.62(2.14$ to 3.19$)$ \\
\hline $4-8$ & 1.63 (1.36 to 1.96$)$ \\
\hline$<4$ & 1 \\
\hline \multicolumn{2}{|c|}{ Oral steroid prescriptions in the 24 months after the IP } \\
\hline Yes & $1.18(1.02$ to 1.37$)$ \\
\hline No & 1 \\
\hline
\end{tabular}

IP, index prescription; LHU, local health unit.
Concerning the pharmacological treatment, 6 out of 10 PAs started with a monotherapy, and during the first 24 months received mainly $\beta 2$-agonists and ICS, with four drugs (salbutamol, fluticasone, montelukast and salmeterol+fluticasone) covering more than $90 \%$ of antiasthmatic prescriptions. The overall pattern of prescribed drugs is quite consistent with findings from other international studies, ${ }^{11-14}$ but did not seem fully adherent to the guideline recommendations. It was unexpected that one out of four children started with ICS monotherapy, and was even more notable that one out of seven children started with a 'third step' therapy (eg, ICS+LABA). This may be explained by the frequency and severity of symptoms, but it appears not rational, since subjects in our study did not receive any asthma drug treatment (with the exception of nebulised formulations) before the IP and those starting with a third-step therapy did not receive a higher number of prescriptions for nebulised antiasthmatics in the 12 months before the IP compared with children with first or second step.

A high percentage of PAs with changes in the initial therapy was observed, in particular among those who started with antiasthmatic polytherapy: for nearly half of them one or more medications were withdrawn during the 2 years after the IP.

The most relevant finding of our study was the low proportion of children with a specialistic/spirometric monitoring, in children $<5$ years, for which difficulties in performing spirometry can exist, and in older children: less than half of PAs starting asthma treatment between the ages of 5 and 8 years, and followed up until they were 7-10 years old, had at least one spirometry testing in a 36-month observation period.

The rate appears extremely low, in particular when considering that our sample was represented by naive patients. The role of spirometry testing compared with the clinical evaluation of symptoms in guiding asthma treatment is debated ${ }^{15-17}$ but in our opinion, and as highlighted by the international guidelines, the evaluation of 
airway function is particularly relevant when the treatment is initiated.

The proportion of children with monitoring is nearly negligible in the 12 months before the IP: in all, in 9 out of 10 PAs the beginning of drug treatment was not preceded by an airway function evaluation.

Moreover, also treatment modifications in most of the cases were not based on spirometry or specialist advice, given that only $30 \%$ of PAs with changes in pharmacotherapy underwent a specialistic/instrumental monitoring.

A low rate of spirometry testing is not peculiar to the Italian setting. ${ }^{12} 131819$ As documented by other authors, ${ }^{13} 19$ the likelihood of receiving a spirometry prescription was greater in high users of antiasthmatics (proxy of a moderate to severe disease) and in older children. Also in the high users, however, the rate of monitoring was unsatisfactory, since 6 out of 10 children never underwent spirometry and/or were visited in a 3-year period.

The rate observed in children having their IP after the fifth birthday was slightly higher than previously reported in Lombardy Region in PAs aged 6-17 years $43 \%$ vs $30 \%) .{ }^{5}$ However, in the current study we expected to find a greater compliance with spirometry monitoring, due to differences between the two studies concerning the involved population (children starting an antiasthmatic treatment for the first time vs all PAs) and the length of observation period (3 years vs 1 year).

The present study did not confirm previous findings of a gender difference in the rate of spirometry testing. ${ }^{5}$ It should be considered, however, that the above differences were observed mainly in adolescence (not considered in this study).

It is quite surprising that the LHU of residence was the main factor influencing the likelihood of receiving a specialist visit and/or a spirometry prescription since wide geographic differences are not expected in a quite homogeneous regional setting.

It is possible that different organisational characteristics and different primary care physicians' attitudes in asthma management exist at the local level, but the finding that the proportion of children with monitoring was lower in LHUs with greater asthma incidence suggests that overdiagnosis or drug overutilisation cannot be excluded, and that there are areas of inappropriateness that should be addressed.

\section{Strengths and limitations}

The main strength of the study was the possibility to monitor the incidence of asthma and the diagnostic and therapeutic pathways in a large population for at least 3 years.

Due to the lack of the diagnosis we had to use drug prescriptions as a proxy of the disease. We used previously validated criteria, but it is possible that a few subjects identified as PAs did not have asthma. In our opinion, this bias has a limited impact, since PAs received drug prescriptions for 2 consecutive years and occasional users were therefore excluded. Moreover, we cannot monitor asthmatic children not receiving drug therapy, with an underestimation of incidence of disease.

It is possible that some subjects had private specialist visits and/or spirometry, but it is likely that this proportion is not relevant.

The potential evaluation of adherence to guidelines was limited mainly to spirometry monitoring because the lack of clinical information (eg, asthma severity) did not allow any inference about the appropriateness of drug treatment, and we were able to monitor changes in pharmacological therapy only in terms of number and type of prescribed drugs, with no data regarding the increase or decrease in dose during the observation period.

In Italy, primary care physicians, in particular family paediatricians, cared for children with mild to moderate asthma, and it is possible that our results reflect the Italian situation and they cannot be generalised to countries with different healthcare organisation. However, similar rates of spirometry monitoring were reported in North European countries and in the USA. ${ }^{12} 131819$

In conclusion, an underuse of spirometry was confirmed in a cohort of children who started drug therapy for asthma. The findings of this study suggest that in most of the cases decisions regarding asthma therapy were taken by primary care physicians on the basis of clinical symptoms without airway function evaluation or allergologist/ pneumologist advice. A gap exists between guideline recommendations and clinical practice and this is particularly evident in a few geographical settings. Educational interventions are therefore needed to implement appropriate asthma management.

Acknowledgements We are grateful to Chiara Pandolfini for language editing.

Contributors PC was involved in planning the study, in data management, and drafted the initial manuscript. AC conceptualised, designed and supervised the study. MC carried out the statistical analyses. $A B 0$ and IF were involved in the data management. LM and ABi were involved in study design. $A B i$ and $M B$ contributed to defining the protocol, and supervised the study. All the authors reviewed and revised the manuscript, and approved the final manuscript as submitted.

Funding The study was funded by the Lombardy Region (EPIFARM Project).

Competing interests None declared.

Patient consent Not required.

Ethics approval No ethics committee approval is required in Italy for epidemiological studies using healthcare administrative databases for research purposes and with individuals identified by an anonymous patient code.

Provenance and peer review Not commissioned; externally peer reviewed.

Open access This is an open access article distributed in accordance with the Creative Commons Attribution Non Commercial (CC BY-NC 4.0) license, which permits others to distribute, remix, adapt, build upon this work non-commercially, and license their derivative works on different terms, provided the original work is properly cited, appropriate credit is given, any changes made indicated, and the use is non-commercial. See: http://creativecommons.org/licenses/by-nc/4.0/.

\section{REFERENCES}

1 Papi A, Brightling C, Pedersen SE, et al. Asthma. Lancet 2018;391:783-800.

2. Wildhaber J, Carroll WD, Brand PL. Global impact of asthma on children and adolescents' daily lives: the room to breathe survey. Pediatr Pulmonol 2012;47:346-57. 
3 British Thoracic Society SIGN. British guideline on the management of asthma: Edinburgh, 2016.

4 Global Initiative for Asthma. Global strategy for asthma management and prevention: Global Initiative for Asthma, 2017.

5. Bianchi M, Clavenna A, Sequi M, et al. Spirometry testing in a population of Italian children: age and gender differences. Respir Med 2012;106:1383-8.

6. Pandolfini C, Campi R, Clavenna A, et al. Italian paediatricians and off-label prescriptions: loyal to regulatory or guideline standards? Acta Paediatr 2005;94:753-7.

7. Bianchi M, Clavenna A, Sequi M, et al. Asthma diagnosis vs. analysis of anti-asthmatic prescriptions to identify asthma in children. Eur J Clin Pharmacol 2011;67:967-8.

8. Furu K, Skurtveit S, Langhammer A, et al. Use of anti-asthmatic medications as a proxy for prevalence of asthma in children and adolescents in Norway: a nationwide prescription database analysis. Eur J Clin Pharmacol 2007;63:693-8.

9 Galassi C, De Sario M, Biggeri A, et al. Changes in prevalence of asthma and allergies among children and adolescents in Italy: 19942002. Pediatrics 2006;117:34-42.

10 Moth G, Vedsted P, Schiøtz P. Identification of asthmatic children using prescription data and diagnosis. Eur J Clin Pharmacol 2007:63:605-11.

11. Engelkes M, Janssens HM, de Jongste JC, et al. Prescription patterns, adherence and characteristics of non-adherence in children with asthma in primary care. Pediatr Allergy Immunol 2016;27:201-8.
12. Jonsson M, Egmar AC, Kiessling A, et al. Adherence to national guidelines for children with asthma at primary health centres in Sweden: potential for improvement. Prim Care Respir J 2012;21:276-82.

13. Moth G, Schiotz PO, Vedsted P. A Danish population-based cohort study of newly diagnosed asthmatic children's care pathway - adherence to guidelines. BMC Health Serv Res 2008;8:130.

14. Zuidgeest MG, Koster ES, Maitland-van der Zee AH, et al. Asthma therapy during the first 8 years of life: a PIAMA cohort study. $J$ Asthma 2010;47:209-13.

15. Bibalo $\mathrm{C}$, Longo $\mathrm{G}$, Ventura $\mathrm{A}$. Treatment of asthma based on symptoms. J Pediatr 2015;166:1324-5.

16. Keeley $\mathrm{D}$, Baxter $\mathrm{N}$. Conflicting asthma guidelines cause confusion in primary care. BMJ 2018;360:k29.

17. Schifano ED, Hollenbach JP, Cloutier MM. Mismatch between asthma symptoms and spirometry: implications for managing asthma in children. J Pediatr 2014;165:997-1002.

18 Ayuk AC, Uwaezuoke SN, Ndukwu Cl, et al. Spirometry in asthma care: a review of the trends and challenges in pediatric practice. Clin Med Insights Pediatr 2017;11:117955651772067.

19. Cabana M, Slish KK, Nan B, et al. Outcomes associated with spirometry for pediatric asthma in a managed care organization. Pediatrics 2006;118:e151-6. 